\title{
George Hevesy Medal Award 2019: call for nomination
}

\author{
A. Chatt ${ }^{1}$ \\ C Akadémiai Kiadó, Budapest, Hungary 2018
}

\section{Call for nomination}

The George Hevesy Medal Award is the premier international award of excellence in radioanalytical and nuclear chemistry. It is awarded to an individual in recognition of excellence through outstanding, sustained career achievements in the fields of pure as well as applied nuclear and radiochemistry, particularly applications to nuclear analytical chemistry. Established originally in 1968 by Prof. Dr. Dr. h.c. Tibor BRAUN, Editor-in-Chief of the Journal of Radioanalytical and Nuclear Chemistry (JRNC), the George Hevesy Medal Award has been given during 1968-86 to 19 distinguished individuals whose contributions have traced and defined the scope and depth of radioanalysis through prolific postwar years of the nuclear era. Their achievements ranged from pioneering radioactivation analysis methodology and applications, through development of radiochemical separation procedures and analytical schemes, to nuclear data, radioisotope production, and radiotracer applications to analysis such as substoichiometric isotopic dilution analysis, automated and computerized systems, Mossbauer spectroscopy, radioactive nanoparticles, and widespread fields of application. This Award has been reactivated in 2000 by Professor Dr. Tibor BRAUN and Professor Dr. Amares CHATT. It is sponsored by JRNC. It was adjudicated by the International Committee on Activation Analysis/Modern Trends in Activation Analysis (ICAA/MTAA; web site: http://www. icaa-mtaa.org) during 2000-15 and by the JRNC Board of the Hevesy Award thereafter. The Award has no monetary

The detailed call for the nomination for the George Hevesy Medal Award 2019 is presented in the "Call for nomination" section. The details of guidelines and regulations of the award are described in the "Guidelines and regulation" section.

A. Chatt

chatt@dal.ca

1 Trace Analysis Research Centre, Department of Chemistry, Dalhousie University, 6274 Coburg Road, PO BOX 15000, Halifax, NS B3H 4R2, Canada value. The Hevesy Award comprises an engraved bronze medal and a citation which are presented at a major international radiochemical conference occurring in the year of the award.

Since the reactivation of the Hevesy Medal Award and its presentation in 2000 at the Methods and Applications of Radioanalytical Chemistry-V (MARC-V) conference held in Kona, Hawai'i, U.S.A., subsequent awards were presented in: 2001 at the Third International Symposium on Nuclear Analytical Chemistry (NAC-III) in Halifax, Canada, and at the Asia-Pacific Symposium on Radiochemistry (APSORC01) in Fukuoka, Japan; 2002 at the Seventh International Conference on Nuclear Analytical Methods in the Life Sciences (NAMLS-7) Including Complementary Isotopic Techniques and Applications held in Antalya, Turkey; 2003 at MARC-VI in Kona; 2004 at the Eleventh Modern Trends in Activation Analysis (MTAA-11) conference held in Guildford, UK; 2005 at NAMLS-8 in Rio de Janeiro, Brazil, at the 1st International Nuclear Chemistry Congress (1st-INCC) in Kusadasi, Turkey, and at APSORC05 in Beijing, China; 2006 at MARC-VII in Kona; 2007 at MTAA-12 in Hachioji, Japan; 2008 at the Seventh International Conference on Nuclear and Radiochemistry (NRC-7) in Budapest, Hungary; 2009 at MARC-VIII in Kona; both 2010 and 2011 awards at MTAA-13 in College Station, Texas, U.S.A.; 2012 at MARC-IX in Kona; 2013 at APSORC13 in Kanazawa, Japan; 2014 at the 17th Radiochemical Conference (RadChem2014) in Mariánské Lázně, Czech Republic; 2015 at MARC-X in Kona, U.S.A. and at MTAA-14 in Delft, The Netherlands; 2016 at the First International Conference on Radioanalytical and Nuclear Chemistry (RANC-2016) in Budapest, Hungary; 2017 at APSORC17 in Jeju Island, Korea; and 2018 at MARC-XI in Kona, U.S.A.

The names (year) of the former awardees are: W. Wayne MEINKE (1968), Albert A. SMALES (1969), Ivan Pavlovich ALIMARIN (1970), Philippe ALBERT and Julien HOSTE (1972), Tibor BRAUN and Juraj TÖLGYESSY (1975), Francesco GIRARDI (1976), Saadia AMIEL and Richard E. WAINERDI (1977), Robert E. JERVIS (1978), Vincent P. GUINN (1979), William S. LYON and Max 
PEISACH (1981), Edward V. SAYRE and Garman HARBOTTLE (1983), Georges AMSEL (1984), Nobuo SUZUKI (1985), Emile A. SCHWEIKERT (1986), Frans DE CORTE (2000), Amares CHATT and Eiliv STEINNES (2001), Enrico SABBIONI (2002), Jeroen J.M. DE GOEIJ (2003), Attila VÉRTES (2004), Nicholas M. SPYROU, Gregory CHOPPIN, Zhifang CHAI (2005), Jan KUČERA (2006), Robert R. GREENBERG (2007), Syed M. QAIM (2008), Richard M. LINDSTROM (2009), Darleane M. HOFFMAN (2010), Peter BODE (2011), Boris F. MYASOEDOV (2012), Rajmund S. DYBCZYŃSKI (2013), Heino NITSCHE (2014), Susanta LAHIRI and Kattesh V. KATTI (2015), Tomoko M. NAKANISHI (2016), Pavel P. POVINEC (2017), and Rolf L. ZEISLER (2018).

One award will be given in 2019 provided a worthy candidate is nominated by the scientists at large and subsequently selected by the Hevesy Medal Award Selection Panel 2019 (HMASP-19). The Hevesy Medal Award 2019 (HMA-19) will be presented at the 2nd International Conference on Radioanalytical and Nuclear Chemistry (RANC-2019) to be held in Budapest, Hungary during 2019 May 05-10.

Nominations of worthy candidates for HMA-19 are widely solicited from the international community of practicing radiochemists and may be initiated by individual colleagues or their institutes including the members of the Editorial Boards of JRNC. There are no restrictions with respect to age, gender, nationality or other to who may be nominated among those whose achievements fall within the guidelines and regulations of the Hevesy Medal Award. A copy of the complete guideline can be obtained from Professor Dr. A. Chatt (chatt@dal.ca), Chair JRNC Board of the Hevesy Award. It is also given below in the "Guidelines and regulation" section.

It is the responsibility of the nominator to prepare a complete, comprehensive and convincing statement of the outstanding achievements and contributions to the field that deserve of recognition through this award. There are no special forms for nomination. Each nomination, to be considered complete, must comprise: (1) a signed nomination letter, (2) two signed co-sponsor letters, (3) a concise but comprehensive 500-1000 word citation stressing the candidate's outstanding and sustained contributions to radioanalytical and nuclear chemistry, (4) a 25-35 word citation for press release, (5) a signed consent letter by the candidate, and (6) a recent complete curriculum vitaé (CV) of the candidate (please follow the details given below). The nominator must ensure that all of these materials are included in the above sequence in a single file prior to sending it. It is preferable to use Adobe Acrobat (.pdf) software for this file although Microsoft Word (.doc, .docx) and Corel WordPerfect (.wpd) can also be used. Additional materials such as more than two co-sponsor letters, web page of the candidate, etc. will not be considered by HMASP-19. The nominations will be considered on their scientific merit, based entirely on the strength of the documentation provided, by HMASP-19 which will not otherwise research the background of the nominee. Only one nomination per candidate will be accepted by HMASP19. The decision of HMASP-19 will be considered final by all parties and may not be appealed or reconsidered, such as on the basis of supplemental documentation.

In order to harmonize the presentation of the complete $\mathrm{CV}$ of the candidates, you are requested to follow the following format. (1) General: Name, Postal and E-mail addresses, Phone numbers, Personal information, Education, Thesis titles, Student Awards, Academic/Government/Industrial positions, Membership in professional organizations, Honors and Awards, Holder of named Chair, Fellowships, Award lectures, etc. (2) Professional Activities: International, National, your own organization, etc. (3) Conferences and Sessions Organized and Chaired. (4) Courses Taught: Undergraduate and Graduate in universities and colleges, international, national and theme-oriented training courses, etc. (5) Thesis Supervision: Ph.D., M.Sc. and B.Sc. theses with dates and names of students as well as thesis titles or topics; clear statement as principal supervisor (solely responsible of thesis), co-supervisor (percentage of supervision), thesis committee member, etc. (6) Supervision of Post-doctoral Fellows, Visiting Scientists, Technicians, colleagues in the group etc. with dates and names of persons. (7) Research Grants and Contracts: titles, organization, and dates. (8) Supervision of other projects such as technical co-operation, co-coordinated research programs, bilateral projects, etc. (9) Publications: (9a) List up to six (6) of your most significant contributions to research and/or to practical applications. This could include published papers, widely distributed documents, patents, computer codes, etc. For each describe the significance in terms of influence on the direction of thought and activity in the target community and in terms of significance to, and use by, other researchers and end users. For collaborative contributions, describe your role and percent of work done by you. (9b) List of refereed contributions in the following order: published, accepted, and submitted. (9c) List of other refereed contributions including letters, notes, communications, review articles, reviewed papers in conference proceedings, monographs, books or book chapters, government publications, etc. (9d) List of non-refereed contributions including the items mentioned in section (3) above. (10) Invited Papers at conferences and workshops, and seminars. (11) Contributed Papers at conferences and workshops. (12) Technical and Research Progress Reports. You could include any other item which is worth noting but not specifically mentioned above. 
This call for HMA-19 nominations can and should be communicated immediately to colleagues who are active in the field to encourage them also to nominate worthy candidates.

Nominations including all materials must be received in Halifax on or before 2018 November 30. It is highly desirable to send the complete nomination package in a single file, preferably in the .pdf format, by e-mail directly to Professor A. Chatt (chatt@dal.ca). There is no need to send paper copies of the nomination package. An acknowledgement of the receipt of the package will be sent to the nominator. The decision of HMASP-19 will be announced by 2019 January 11.

\section{Guidelines and regulations}

1. The Hevesy Medal has been and will continue to be awarded to individuals (as distinct from groups or teams) in recognition of and to honor outstanding sustained career achievements in radioanalytical and nuclear chemistry.

2. Traditionally the award has been made to honor individuals who continue to be active in the field although consideration of recent retirees is not excluded.

3. Candidates being nominated are assumed to have consented to having their $\mathrm{CV}$ and credentials reviewed (in confidence) by the HMASP and the award sponsor; it is the responsibility of the nominator to ensure that this consent has been given (also see paragraph 2.4.3). The consent letter must also categorically state that "in the event the Hevesy Medal is awarded to me then I agree to attend the conference where the medal is to be presented, pay for all costs including registration fee, travel and living expenses, deliver the Award Lecture, and submit in timely manner a paper covering the lecture to the conference organizers for publication in JRNC"'.

4. Only one nomination per candidate will be accepted by the HMASP.

4.1. If the HMASP becomes aware of the intention of more than one group to nominate the same candidate, action would be taken by Prof. Chatt (as the Chair of the JRNC Board of the Hevesy Award) to put the groups involved in communication with instructions that they amalgamate their submissions into a single nomination.

4.2. In case of an uncooperative group or unawareness of multiple nominations being prepared, the first complete nomination received will be accepted and any subsequent nominations for the same candidate be rejected.

4.3. In this respect, the nominee, who would normally be aware of intentions to nominate, should act to avoid multiple nominations to be submitted (which actions might be construed as attempts to unduly influence the panel).

5. All nominations for the Hevesy Medal Award(s) will be reviewed and adjudicated by HMASP named by the JRNC Board of the Hevesy Award.

5.1. The HMASP will consist of a total of nine members.

5.2. In each year of the award, the Chair of the JRNC Board of the Hevesy Award will select five members of the HMASP. He/she will contact prominent nuclear and radiochemists including the past Hevesy awardees and Editorial Advisory Board members of the JRNC. One or two members could also be selected on the basis of their expertise in certain areas of nuclear and radiochemistry and/or to represent geographical areas. The highest caliber of the person should be the deciding factor for membership.

5.3. The Chair of the conference where the Hevesy Medal Award will be presented during that year will serve as the sixth member of HMASP provided he/she is a scientist in good standing and he/she is not a candidate, nominator, or a cosponsor of the Award. If yes, then another notable scientist from the same geographic area could be selected.

5.4. The seventh, eighth and ninth members of the HMASP are the Honorary Editor-in-Chief and Founder of JRNC (Professor Dr. Tibor BRAUN), Editor-in-Chief of JRNC (Dr. Zsolt RÉVAY), and the Chair of the JRNC Board (Professor Dr. A. CHATT).

5.5. The Chair of the JRNC Board of the Hevesy Award will either serve as or help select the Chair of HMASP among its nine members.

6. Individual members of the HMASP may not cosponsor or otherwise assist or participate in the nomination of any candidate; further, they must disclose in advance any conflict of interest in their participation in the panel's decisions. Any member who becomes a nominee, or who decides to cosponsor a candidate will be considered to have withdrawn from the panel at that point and will no longer be privy to documentation received for candidates.

7. The nominee, nominator and co-sponsors should not knowingly contact any of the HMASP members in the 
context of the current nomination. In the event such a contact is made, the candidature of the nominee will be rejected.

8. The call for nominations of the Hevesy Medal Award will be widely circulated. It will be published in JRNC in both digital and printed forms. It will be sent to national nuclear chemistry societies in various countries with a request to circulate it among their members and interested parties. It will be posted on the web site of the conference where the award is being presented in that year. It may also be electronically circulated to the participants at international conferences such as MTAA, MARC, NAC, NAMLS, APSORC and RadChem. The members of the Editorial Advisory Board of the JRNC will also be included into the mailing list. The Chair of the JRNC Board of the Hevesy Award will generally be responsible for this advertisement.

9. All submissions for the nomination of the Award will be made electronically to the Chair of the JRNC Board of the Hevesy Award.

10. Valid nominations submitted for the previous Hevesy Medal Award competition should be updated and resubmitted for further consideration, if so desired.
11. Evaluation of the candidate's merit for the Award will be based on the completeness and cogency of the submitted documentation and supporting letters. The HMASP will not research candidates' qualifications, achievements, past distinctions, or other information but will form their judgment solely on the strength of the case made for the candidate in the submitted documentation.

12. The HMASP's decision will be considered final by all parties and may not be appealed or reconsidered, such as on the basis of supplemental documentation. The HMASP can decide on a majority vote not to award the Medal in a given year if the qualities of the candidates nominated fall short of the standards worth the award.

13. The identity of candidates nominated for the Hevesy Medal Award and all associated documentation will be kept confidential within the HMASP and the Editorial Office of the JRNC.

14. The awardee(s) will be invited to present the award lecture at an international conference on nuclear or radioanalytical chemistry selected by the JRNC Board of the Hevesy Award. Details of the Award and the candidate's Laudation will be published in JRNC. 